\title{
Lowered cutoff of lymph node fine-needle aspiration thyroglobulin in thyroid cancer patients with serum anti-thyroglobulin antibody
}

\author{
Kwanhoon Jo', Min-Hee Kim ', Yejee Lim', So-Lyung Jung², Ja-Seong Bae', \\ Chan-Kwon Jung ${ }^{4}$, Moo-Il Kang ${ }^{1}$, Bong-Yun Cha' ${ }^{1}$ and Dong-Jun Lim ${ }^{1}$ \\ Division of Endocrinology and Metabolism, Departments of ${ }^{1}$ Internal Medicine, ${ }^{2}$ Radiology, ${ }^{3}$ Surgery and \\ ${ }^{4}$ Hospital Pathology, College of Medicine, Seoul St Mary's Hospital, The Catholic University of Korea, \\ \#505 Banpo-Dong, Seocho-Gu, Seoul 137-701, Korea
}

Correspondence should be addressed to D-J Lim

Email

Idj6026@catholic.ac.kr

\begin{abstract}
Objective: Fine needle aspiration cytology (FNAC) and measurement of thyroglobulin (Tg) in needle washout (FNA-Tg) are recommended for the diagnosis of metastatic or recurrent lymph nodes (LNs) in differentiated thyroid cancer (DTC). However, the effect of serum Tg antibody (TgAb) on FNA-Tg levels still remains unclear in the preoperative setting. We analyze the interference of serum TgAb on FNA-Tg levels as proof of concept in the diagnostic advantage of serum TgAb combined with FNA-Tg.

Subjects and methods: A total of 370 suspicious cervical LNs from 273 patients with DTC were included. The primary tumor was confirmed as DTC on preoperative pathology in all patients. We performed FNA-Tg measurement and FNAC on suspicious LNs and evaluated the diagnostic performance of FNAC and FNA-Tg according to TgAb status. Final diagnoses were confirmed by histological examination of excised specimens or by follow-up ultrasonography for at least 6 months. Results: Data from 273 subjects with suspicious 370 LNs were evaluated. Fifty-five LNs (14.9\%) were from TgAb+ positive serum TgAb $(\mathrm{TgAb}+)$ patients. Serum Tg and FNA-Tg levels were significantly lower in patients with $\mathrm{TgAb}+$ than in those with TgAb-negative (TgAb-). Final pathology confirmed 109 LNs (29.5\%) asmalignant. Diagnostic performance of FNA-Tg at the same cutoff level was lower in the TgAb + than TgAb - group. FNA-Tg cutoff levels determined by ROC curve were lower in the $\operatorname{TgAb}+$ group.

Conclusion: The results suggested that the cutoff value of FNA-Tg should be lowered in suspicious LN before thyroidectomy in thyroid cancer patients with TgAb.
\end{abstract}

\section{Introduction}

Thyroid cancer incidence has increased over the last decade worldwide. Although differentiated thyroid cancer (DTC) shows good prognosis, $5 \%$ to $20 \%$ of patients treated with total thyroidectomy developed cervical lymph node (LN) metastases at the time of diagnosis or during postoperative follow-up $(1,2)$.

Fine needle aspiration cytology (FNAC) is recommended for diagnosis of metastatic LNs in thyroid cancer $(3,4)$. When
(C) 2015 European Society of Endocrinology Printed in Great Britain
FNAC results are nondiagnostic or indeterminate, thyroglobulin (Tg) measurement in washout fluid of FNA (FNA-Tg) may improve the diagnostic performance of FNA. Many previous studies reported that FNA-Tg is more sensitive than FNAC, and a combination of FNAC and FNA-Tg can improve diagnostic accuracy for detecting metastasis $(4,5,6,7,8,9,10$, $11,12,13)$. Therefore, recent guidelines indicate FNAC with FNA-Tg for all suspicious LNs of thyroid cancer $(14,15,16)$.

Published by Bioscientifica Ltd. 
Positive serum $\mathrm{Tg}$ antibody $(\mathrm{Tg} A b)$ is known to lower serum $\mathrm{Tg}$ (sTg) levels, and this may be even more important in DTC patients prior to thyroidectomy and/or radioactive iodine therapy in whom a higher rate of positive $\mathrm{TgAb}$ has been reported (17). Thus, the high rate of positive serum $\mathrm{TgAb}$ can lower sTg levels and influence FNA-Tg levels, which is possibly associated with altered diagnostic accuracy. Few prior studies indicate the potential interference of $\mathrm{TgAb}$ on FNA-Tg levels (5). However, the influence of $\mathrm{TgAb}$ on FNA-Tg remains unclear; furthermore, the status of the thyroid operation had not been considered in most of the earlier studies.

We aimed to determine the effects of serum $\mathrm{TgAb}$ on the cutoff value of FNA-Tg to detect metastatic lesions in suspicious LNs of preoperative DTC patients and to improve the diagnostic accuracy of FNA and FNA-Tg.

\section{Subjects and methods}

\section{Patients}

All three inclusion criteria should be satisfied before study enrollment: i) consecutive patients should have confirmed diagnosis of primary DTC, ii) ultrasound-guided FNAC were performed along with FNA-Tg measurement for suspicious LN, and iii) FNAC, FNA-Tg and TgAb measurement should be done before surgery.

Initially, 1050 LNs in 661 patients with suspicious LNs detected by neck ultrasound were targeted at a tertiary referral hospital between May 2011 and December 2013. Two hundred and seventy-three patients with 474 LNs who underwent lobectomy or total thyroidectomy before FNA were excluded. Additionally, 388 patients with 206 LNs were excluded due to no primary thyroid cancer $(n=2)$, no follow-up or confirmation of LNs by pathology $(n=155)$ and no data of preoperative sTg and $\mathrm{TgAb}$ $(n=49)$ (Fig. 1). A total of 273 patients with 370 LNs were evaluated according to the presence or absence of $\mathrm{TgAb}$. The institutional review board approved the study (KC14RISI0259).

\section{Serum Tg, TgAb, FNAC and FNA-Tg measurement}

Both serum and FNA washout $\mathrm{Tg}$ levels were measured using an immunoradiometric assay kit (CIS Bio International, Saclay, France), with a functional sensitivity of $0.7 \mathrm{ng} / \mathrm{ml}$. Serum TgAb was measured by a competitive RIA kit (ZenTech, Angleur, Belgium). Positive TgAb was defined as serum $\mathrm{TgAb}$ of $\geq 70 \mathrm{IU} / \mathrm{ml}$; negative $\mathrm{TgAb}$ as a serum $\mathrm{TgAb}$ of $<70 \mathrm{IU} / \mathrm{ml}$.

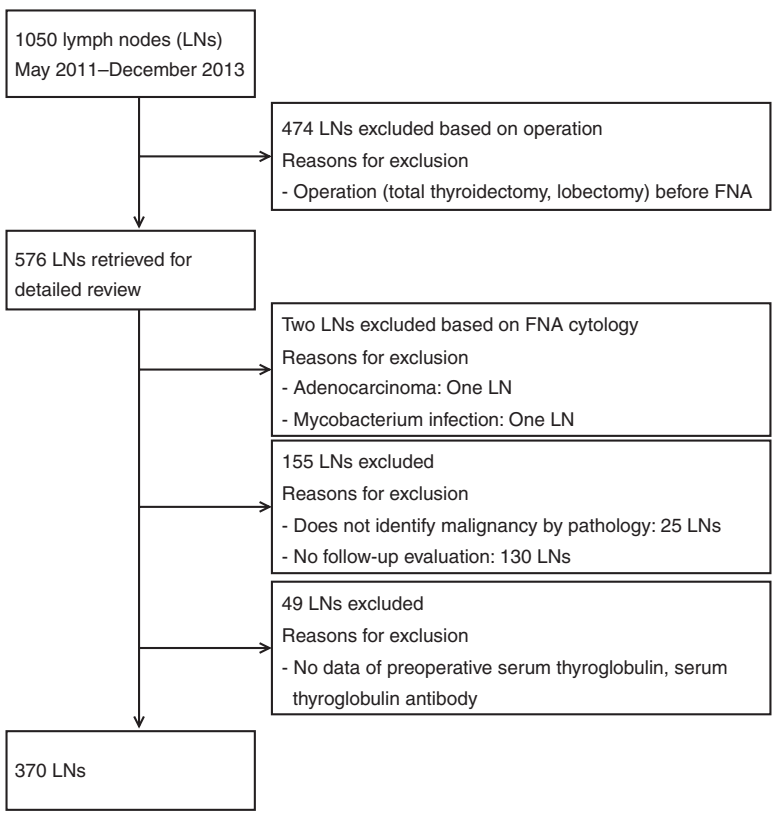

Figure 1

Case selection.

Ultrasound-guided FNAC was performed by one of several radiologists with the use of a 23-gauge needle. While a liquid-based cytology (LBC) was used in the diagnosis of primary thyroid tumor (18), FNAC for suspicious LN was evaluated by the conventional method: the aspirates were immediately smeared on slides, fixed in 95\% ethanol and processed by both hematoxylin and eosin (H\&E) and Papanicolaou stain. The same needle and syringe were rinsed with $2 \mathrm{ml}$ of normal saline, and the washout fluid was submitted for FNA-Tg measurement.

\section{FNAC and final pathology}

Cytology findings of the LNs reviewed by experienced pathologists were categorized as non-diagnostic, benign and metastatic papillary thyroid carcinoma (PTC; suspicious malignancy, malignancy) $(5,10,19,20,21)$.

Final outcome was confirmed by post-operative pathology in malignant LNs. When LNs were suspicious for malignancy in ultrasonography but cytology results revealed benign LNs, LN dissection and histopathologic confirmation were performed if there were malignant LNs in the same compartment $(7,13)$. Otherwise, decreased or same-size LNs in follow-up ultrasound after 6-12 months were defined as benign in the final outcome (21). 
Table 1 Patient characteristics according to TgAb.

\begin{tabular}{|c|c|c|c|}
\hline Characteristics & $\operatorname{TgAb}-$ & $\operatorname{Tg} \mathbf{A b}+$ & $\begin{array}{c}P \\
\text { value }\end{array}$ \\
\hline $\begin{array}{l}\text { Number of } \\
\text { patients }(\%)^{a}\end{array}$ & 218 (79.9) & $55(20.1)$ & \\
\hline Age & $47.1 \pm 12.7$ & $45.5 \pm 11.0$ & 0.369 \\
\hline Male sex $(\%)$ & $47(21.6)$ & $5(9.1)$ & 0.036 \\
\hline $\begin{array}{l}\text { Preoperative } \\
\text { serum Tg } \\
\text { (ng/ml) }\end{array}$ & $13.6(0.2-557.6)$ & $7.2(0.0-71.2)$ & 0.040 \\
\hline $\begin{array}{l}\text { Preoperative } \\
\text { TgAb (IU/ml) }\end{array}$ & $12.6(0.1-69.5)$ & $209.2(73.0-8560.0)$ & 0.000 \\
\hline $\begin{array}{l}\text { Number of lymph } \\
\text { nodes (\%) }\end{array}$ & $289(78.1)$ & $81(21.9)$ & \\
\hline FNA-Tg (ng/ml) & $0.4(0.0-1698.5)$ & $0.9(0.1-1121.2)$ & 0.026 \\
\hline
\end{tabular}

aData are expressed as mean \pm s.D. or median (range).

\section{Statistical analysis}

Data were expressed as mean \pm s.D. or median (minimummaximum value). We performed receiver operating characteristic (ROC) curve analysis to confirm the cutoff level of FNA-Tg. Diagnostic performances of FNA and FNATg were evaluated with respect to sensitivity, specificity, positive predictive value (PPV), negative predictive value (NPV) and accuracy. The $\chi^{2}$ test or Fisher exact test was used to determine the differences between benign and metastatic LNs according to categorical variables. Statistical significance was determined when the $P$ value was $<0.05$. All reported $P$ values are two-sided. All analyses were conducted by SPSS Software (version 18.0).

\section{Results}

\section{Patient and LN characteristics}

Finally, 273 patients with 370 LNs were included in this study. The median patient age at the time of FNA was 45 years (range 21-81) and 221 (81\%) were female
(Table 1). Of the 273 patients, 218 (79.9\%) were in the $\mathrm{TgAb}$ negative $(\mathrm{TgAb}-)$ group and 55 (20.1\%) in the TgAb positive $(\mathrm{TgAb}+)$ group. There was no significant difference in age but sex distribution between groups. However, FNA-Tg and preoperative serum Tg levels were significantly lower in the $\mathrm{TgAb}+$ group vs $\mathrm{TgAb}-$ group (Table 1 ).

Two hundred and sixty-one (70.5\%) of 370 LNs were benign (Table 2); 55 LNs were confirmed by surgery and subsequent postoperative pathology and 206 LNs by follow-up US. The other 109 LNs (29.5\%) were confirmed as malignant on postoperative pathology (Table 2 and Fig. 2). According to the final outcome and TgAb status, we compared four LN groups (Table 2). In benign LNs, there were no significant differences in FNA-Tg and preoperative sTg between the TgAb + and TgAb - groups; however, in malignant LNs, median sTg and FNA-Tg levels were significantly lower in patients with serum $\mathrm{TgAb}+$ than in those with $\mathrm{TgAb}-(8.2$ vs $29.7 \mathrm{ng} / \mathrm{ml}, P=0.000 ; 398.5$ vs $881.3 \mathrm{ng} / \mathrm{ml}, P=0.012$ ).

\section{Diagnostic performance of FNAC}

Among 109 metastatic LNs, FNAC resulted in a correct diagnosis in 92 cases but faild to diagnose 17 cases with a resultant $84.4 \%$ sensitivity and $99.6 \%$ specificity. Among the 17 misdiagnosed metastatic LNs, 15 had been reported as benign, one unsatisfactory and one instance of macrophages on FNAC. Among 261 benign LNs, 259 LNs were correctly diagnosed as benign in FNAC but one LN showed malignancy and another LN as unsatisfactory.

\section{FNA-Tg and final outcome}

We compared sensitivity, specificity, PPV, NPV and diagnostic accuracy of FNA-Tg levels of LN according to the functional sensitivity of $\operatorname{Tg}(0.7 \mathrm{ng} / \mathrm{ml})(3,22)$ and the value determined by ROC curve $(6.0 \mathrm{ng} / \mathrm{ml})$, with those of FNAC (Table 4 ). In addition, FNA-Tg/sTg ratio was also

Table 2 Lymph node characteristics according to final outcome and $\operatorname{TgAb}$.

\begin{tabular}{l} 
Final outcome \\
\hline Number of lymph \\
nodes \\
FNA-Tg (ng/ml) \\
Preoperative serum \\
Tg (ng/ml) \\
Preoperative TgAb \\
(IU/ml)
\end{tabular}

\begin{tabular}{cc}
$\frac{2}{c}$ Benign \\
\hline 200 & $\frac{\mathrm{TbAb}^{\mathrm{b}}}{61}$ \\
$0.2(0.0-1253.7)$ & $0.3(0.1-833.5)$ \\
$11.5(0.2-366.2)$ & $6.8(0.0-71.2)$ \\
$14.2(0.1-66.9)$ & $218.9(75.9-8560.0)$ \\
\end{tabular}

\begin{tabular}{c}
\hline Malig \\
\hline TbAb-c \\
\hline 89 \\
$29.7(0.4-557.6)$ \\
$12.5(0.3-69.5)$
\end{tabular}

\begin{tabular}{|c|c|c|c|}
\hline \multicolumn{4}{|c|}{$P$ value } \\
\hline$a$ vs $b$ & $c$ vs d & a vs c & $b$ vs $d$ \\
\hline 0.930 & 0.012 & 0.000 & 0.000 \\
\hline 0.127 & 0.000 & 0.004 & 0.767 \\
\hline 0.001 & 0.013 & 0.004 & 0.625 \\
\hline
\end{tabular}




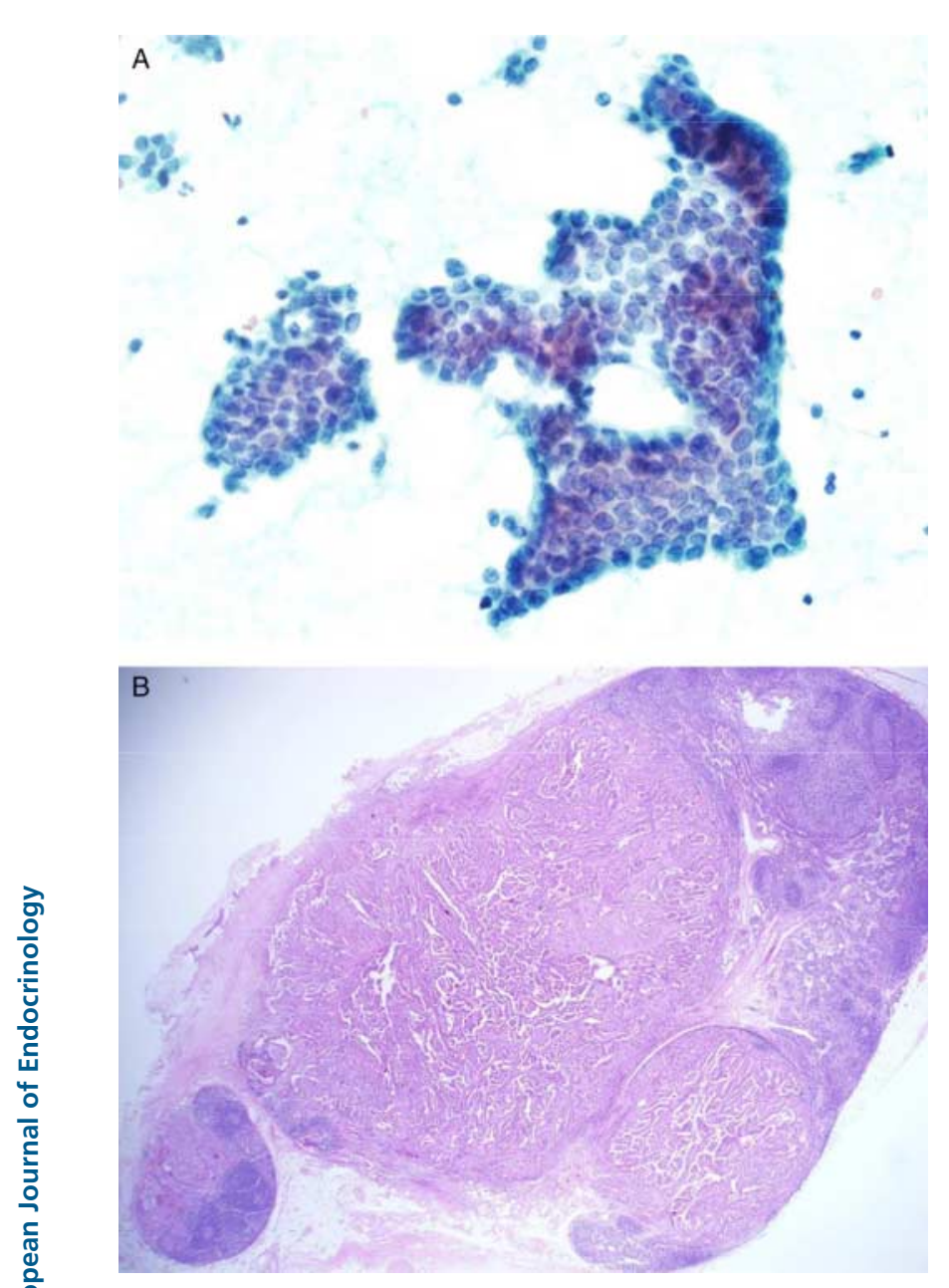

\section{Figure 2}

A 72-year-old female presented with thyroid nodule and a suspicious lymph node in the left side of the neck. She underwent fine-needle aspiration cytology (FNAC) with washout thyroglobulin (FNA-Tg) for lymph node. Her FNA-Tg, serum $\mathrm{Tg}$, and serum $\mathrm{Tg}$ antibody were $809.0 \mathrm{ng} / \mathrm{ml}, 18.5 \mathrm{ng} / \mathrm{ml}$ and $19.1 \mathrm{lU} / \mathrm{ml}$ respectively. (A) FNAC of cervical lymph node shows cellular clusters with characteristic nuclear features of papillary thyroid carcinoma (Papanicolaou stain, $\times 400$ ). (B) On pathologic examination of resected specimen, metastatic papillary carcinoma is seen within the lymph node (H\&E stain, $\times 12$ ).

A full colour version of this figure is available at http://dx.doi.org/ 10.1530/EJE-15-0344.

used as a cut-off value to diminish the influence of sTg in preoperative patients $(19,23)$ (Table 4$)$

FNAC alone showed the lowest sensitivity (88.4\%) but the highest specificity (99.6\%). With FNA-Tg 0.7 added to FNAC, sensitivity was the highest (99.1\%) but PPV was the lowest (63.9\%). The combination of FNA-Tg 6.0 and FNAC showed the best diagnostic accuracy, with 97.3\% sensitivity, 94.6\% specificity, 88.3\% PPV, 98.8\% NPV and $95.4 \%$ accuracy. The diagnostic value of FNA-Tg/sTg ratio was inferior to that of FNA-Tg alone.

All combinations of FNA-Tg and FNAC showed higher sensitivity and NPV than FNAC or FNA-Tg alone.

\section{Optimal cutoff values of FNA-Tg in determining malignant LNs according to TgAb status}

Diagnostic performance of FNAC, all FNA-Tg levels and their combinations were lower in the $\mathrm{TgAb}+$ group than $\mathrm{TgAb}$ - group. When applying ROC curve cutoff of the entire group $(6.0 \mathrm{ng} / \mathrm{ml})$, sensitivity and PPV were reduced by $>10 \%$ in the $\mathrm{TgAb}+$ group, as compared to the $\mathrm{TgAb}-$ group (Table 5). Comparing FNA-Tg alone with FNAC combined with FNA-Tg at each cutoff value of FNA-Tg, there was no significant improvement in diagnostic performance found in the $\mathrm{TgAb}$ - group, but sensitivity was greatly improved (85-95\%) in the $\mathrm{TgAb}+$ group. Sensitivity and NPV improved when applying a lower cutoff value of FNA-Tg $(6.0 \mathrm{ng} / \mathrm{ml}$ to $2.5 \mathrm{ng} / \mathrm{ml})$ combined with FNAC in the $\mathrm{TgAb}+$ group. On the contrary, $\mathrm{TgAb}$ - group showed better diagnostic performance when applying a higher cutoff of FNA-Tg $(6.0 \mathrm{ng} / \mathrm{ml}$ to $8.5 \mathrm{ng} / \mathrm{ml}$ ) (Table 5).

\section{Presentation of LNs with discordant results}

FNAC results and postoperative pathology were not in agreement in 19 LNs of the 19 patients: 15 LNs that were negative for malignancy in FNAC were malignant on postoperative pathology (Table 6). Four patients out of 19 discordant cases showed positive TgAb (21.1\%). Among 15 malignant LNs, only three LNs showed FNA-Tg of $<6 \mathrm{ng} / \mathrm{ml}$ (cases 1-3). Case 2 with positive TgAb $(173.7 \mathrm{IU} / \mathrm{ml})$ had $2.8 \mathrm{ng} / \mathrm{ml}$ of FNA-Tg, which could have been detected by the cutoff value $(2.5 \mathrm{ng} / \mathrm{ml})$ with ROC analysis in the $\mathrm{TgAb}+$ group.

Table 3 Correlation of FNAC results with postoperative pathology in suspicious lymph node.

\begin{tabular}{|c|c|c|c|}
\hline \multirow[b]{2}{*}{ FNAC results } & \multicolumn{2}{|c|}{ Postoperative pathology } & \multirow[b]{2}{*}{ Total } \\
\hline & Benign & Malignancy & \\
\hline Benign & 259 & 15 & 274 \\
\hline Malignant & 1 & 92 & 93 \\
\hline Unsatisfactory & 1 & 1 & 2 \\
\hline Other & 0 & 1 & 1 \\
\hline Total & 261 & 109 & 370 \\
\hline
\end{tabular}


Table 4 Comparison between diagnostic performances of FNAC, FNA-Tg and FNA-Tg/sTg ratio.

\begin{tabular}{|c|c|c|c|c|c|}
\hline Diagnostic performance & Sensitivity & Specificity & PPV & NPV & Accuracy \\
\hline FNAC & 84.4 & 99.6 & 98.9 & 93.9 & 95.1 \\
\hline FNA-Tg $0.7^{a}$ & 98.2 & 77.0 & 64.1 & 99.0 & 83.2 \\
\hline FNA-Tg $6.0^{\mathrm{b}}$ & 95.4 & 95.0 & 88.9 & 98.0 & 95.1 \\
\hline FNA-Tg/sTg 1 & 88.1 & 93.9 & 85.7 & 95.0 & 92.2 \\
\hline FNA-Tg/sTg $0.4^{\mathrm{b}}$ & 92.7 & 88.9 & 77.7 & 96.7 & 90.0 \\
\hline FNAC + FNA-Tg $0.7^{a}$ & 99.1 & 76.6 & 63.9 & 99.5 & 83.2 \\
\hline FNAC + FNA-Tg $6.0^{\mathrm{b}}$ & 97.3 & 94.6 & 88.3 & 98.8 & 95.4 \\
\hline FNAC+FNA-Tg/sTg 1 & 92.7 & 93.5 & 85.6 & 96.8 & 93.2 \\
\hline FNAC+FNA-Tg/sTg $0.4^{\mathrm{b}}$ & 96.3 & 88.5 & 77.8 & 98.3 & 90.8 \\
\hline
\end{tabular}

${ }^{\text {a}}$ Functional sensitivity of thyroglobulin assay.

${ }^{\mathrm{b}}$ Cutoff value according to ROC.

Another two non-diagnostic LNs were metastatic in the final report (cases 16 and 17) with FNA-Tg levels of $>6 \mathrm{ng} / \mathrm{ml}$, without $\mathrm{TgAb}$. Case 18 , initially misdiagnosed as papillary carcinoma by FNAC, was finally diagnose as parathyroid hyperplasia (Table 6).

\section{Discussion}

Although many clinical studies composed of total thyroidectomy patients evaluated optimal cutoff values of FNA-Tg levels in detecting metastatic LNs, there are no reliable studies on cutoff values of FNA-Tg levels in preoperative patients. Several studies were conducted on preoperative patients $(7,13,23,24,25)$ but the small number of cases precluded any strong conclusion and the $\mathrm{TgAb}$ status was not considered. Prior studies also showed the effect of TgAb status on FNA-Tg levels but did not consider the operative status $(5,10,26)$.

In this study, preoperative patients who were diagnosed with PTC and had LNs with metastatic feature in US underwent FNAC and $\mathrm{Tg}$ estimation in washout fluid of FNAC. Our study confirmed that positive serum TgAb lowered FNA-Tg levels and influenced the diagnostic accuracy of FNA-Tg in suspicious LNs of preoperative patients.

All preoperative patients had normal thyroid tissues, which indicated an increased proportion of $\mathrm{TgAb}$-positive patients, as compared to thyroidectomy patients with or without radioiodine remnant ablation (27) As increased serum TgAb levels lower sTg levels (28), we hypothesized that increased serum $\mathrm{TgAb}$ levels in thyroid cancer patients have lower FNA-Tg levels and subsequently

Table 5 Comparison between diagnostic performances of FNA-Tg, FNA-Tg/sTg ratio according toTgAb status.

\begin{tabular}{|c|c|c|c|c|c|}
\hline Diagnostic performance & Sensitivity & Specificity & PPV & NPV & Accuracy \\
\hline \multicolumn{6}{|l|}{$\operatorname{TgAb}-$} \\
\hline FNAC & 85.4 & 99.5 & 98.7 & 93.9 & 95.2 \\
\hline FNA-Tg $0.7^{a}$ & 98.9 & 81.0 & 69.8 & 99.4 & 86.5 \\
\hline FNA-Tg $6.0^{\mathrm{b}}$ & 97.8 & 96 & 91.6 & 99.0 & 96.5 \\
\hline FNA-Tg $8.5^{c}$ & 96.6 & 96.5 & 92.5 & 98.5 & 96.5 \\
\hline FNAC+FNA-Tg $0.7^{a}$ & 98.9 & 80.5 & 69.3 & 99.4 & 86.2 \\
\hline FNAC + FNA-Tg $6.0^{\mathrm{b}}$ & 97.8 & 95.5 & 90.6 & 99.0 & 96.2 \\
\hline FNAC + FNA-Tg $8.5^{\mathrm{C}}$ & 96.6 & 96.0 & 91.5 & 98.5 & 96.2 \\
\hline \multicolumn{6}{|l|}{$\operatorname{TgAb}+$} \\
\hline FNAC & 80.0 & 100.0 & 100.0 & 93.9 & 95.1 \\
\hline FNA-Tg $0.7^{a}$ & 95.0 & 63.9 & 46.3 & 97.5 & 71.6 \\
\hline FNA-Tg $6.0^{\mathrm{b}}$ & 85 & 91.8 & 77.3 & 94.9 & 90.1 \\
\hline FNA-Tg $2.5^{d}$ & 95 & 83.6 & 65.5 & 98.1 & 86.4 \\
\hline FNAC + FNA-Tg $0.7^{a}$ & 100.0 & 63.9 & 47.6 & 100.0 & 72.8 \\
\hline FNAC + FNA-Tg $6.0^{\mathrm{b}}$ & 95.0 & 91.8 & 79.2 & 98.3 & 92.6 \\
\hline$F N A C+F N A-T g 2.5^{d}$ & 100.0 & 83.6 & 66.7 & 100.0 & 87.7 \\
\hline
\end{tabular}


Table 6 Clinical characteristics of lymph nodes with discordant results between preoperative FNAC and postoperative pathology.

\begin{tabular}{|c|c|c|c|}
\hline LNs & Gender & Age & FNAC \\
\hline 1 & $\mathrm{~F}$ & 53 & Negative for malignancy \\
\hline 2 & $\mathrm{~F}$ & 45 & Negative for malignancy \\
\hline 3 & $\mathrm{~F}$ & 49 & $\begin{array}{l}\text { Negative for malignancy, many } \\
\text { small and large polymorphic } \\
\text { lymphoid cells }\end{array}$ \\
\hline 4 & $\mathrm{~F}$ & 35 & Negative for malignancy \\
\hline 5 & $\mathrm{~F}$ & 60 & Negative for malignancy \\
\hline 6 & $\mathrm{~F}$ & 44 & Negative for malignancy \\
\hline 7 & $\mathrm{~F}$ & 36 & Negative for malignancy \\
\hline 8 & $\mathrm{~F}$ & 49 & Negative for malignancy \\
\hline 9 & $\mathrm{~F}$ & 36 & Negative for malignancy \\
\hline 10 & $\mathrm{~F}$ & 49 & Negative for malignancy \\
\hline 11 & $\mathrm{~F}$ & 39 & $\begin{array}{l}\text { Negative for malignancy. } \\
\text { Mainly blood and some } \\
\text { inflammatory cells }\end{array}$ \\
\hline 12 & $\mathrm{~F}$ & 47 & Negative for malignancy \\
\hline 13 & M & 63 & Negative for malignancy \\
\hline 14 & $\mathrm{~F}$ & 60 & Negative for malignancy \\
\hline 15 & M & 43 & Negative for malignancy \\
\hline 16 & M & 34 & $\begin{array}{l}\text { Non-diagnostic specimen; only } \\
\text { fibrovascular and muscular tissue }\end{array}$ \\
\hline 17 & M & 60 & $\begin{array}{l}\text { Other; many hemosiderin-laden } \\
\text { macrophages }\end{array}$ \\
\hline 18 & $\mathrm{~F}$ & 40 & Papillary carcinoma \\
\hline 19 & $\mathrm{~F}$ & 38 & Unsatisfactory; very low cellularity \\
\hline
\end{tabular}

\begin{tabular}{|c|c|c|c|c|}
\hline Postoperative pathology & FNA-Tg & TgAb & $\begin{array}{c}\text { Serum } \\
\text { Tg }\end{array}$ & $\begin{array}{c}\text { Cervical lymph } \\
\text { node level }\end{array}$ \\
\hline Papillary carcinoma & 0.2 & 1.1 & 14.4 & L4 \\
\hline Papillary carcinoma & 2.8 & 173.7 & 23.4 & $\mathrm{R} 2$ \\
\hline Papillary carcinoma & 4.8 & 39.3 & 39.7 & R4 \\
\hline Papillary carcinoma & 6.6 & 11.4 & 2.3 & R4 \\
\hline Papillary carcinoma & 7.9 & 1552.2 & 9.1 & R3 \\
\hline Papillary carcinoma & 9.3 & 24.4 & 11.8 & L4 \\
\hline Papillary carcinoma & 26.0 & 8.6 & 514.4 & L3 \\
\hline Papillary carcinoma & 27.1 & 191.1 & 36.9 & R6 \\
\hline Papillary carcinoma & 29.4 & 664.2 & 71.2 & R3 \\
\hline Papillary carcinoma & 36.2 & 13.0 & 28.9 & L4 \\
\hline Papillary carcinoma & 890.8 & 22.0 & 15.2 & R4 \\
\hline Papillary carcinoma & 1037.5 & 15.3 & 28.4 & $\mathrm{R} 2$ \\
\hline Papillary carcinoma & 1195.5 & 13.0 & 5.7 & R3 \\
\hline Papillary carcinoma & 1195.6 & 9.2 & 156.3 & R4 \\
\hline Papillary carcinoma & 1295.7 & 6.8 & 49.6 & L4 \\
\hline Papillary carcinoma & 413.8 & 12.1 & 25.4 & L4 \\
\hline Papillary carcinoma & 800.3 & 1.4 & 122.9 & L4 \\
\hline Parathyroid hyperplasia & 0.3 & 10.7 & 14.7 & R6 \\
\hline Negative for malignancy & 0.0 & 6.4 & 6.1 & R4 \\
\hline
\end{tabular}

L, left; R, right; number, cervical lymph node area $(2,3,4,6)$.

lower diagnostic accuracy of FNA-Tg in patients with suspicious LNs. Baskin et al. (26) first suggested that the measurement of FNA-Tg from LN was unlikely to be affected by the presence of TgAb in the peripheral blood, possibly because the intracellular $\mathrm{Tg}$ is not exposed to circulating $\mathrm{TgAb}$, from the two patients who showed FNATg levels of 24.9 and $67.5 \mathrm{ng} / \mathrm{ml}$ respectively but positive $\mathrm{TgAb}$ and undetectable sTg. Boi et al. (5) also concluded that the diagnostic performance of FNA-Tg seems to be not substantially affected by $\mathrm{TgAb}$, although $\mathrm{TgAb}$ in FNA washout may lower FNA-Tg in a few selected cases. The rationale of no interference by $\mathrm{TgAb}$ is as follows: In metastatic LNs, FNA-Tg levels are much higher than TgAb levels that exist in the washout fluid. It can overcome interference by $\mathrm{TgAb}$ due to saturated $\mathrm{TgAb}$-binding sites (5). Diluted $\mathrm{TgAb}$ in washout fluid (most likely being 1:50 or higher) (25) result in absence or scarcity of TgAb within the LNs.

However, one recent study by Jeon et al. (21) demonstrated that high serum TgAb levels could lower FNA-Tg levels, from 25 suspicious LNs in 14 patients who underwent total thyroidectomy and radioiodine remnant ablation. They showed a diagnosis based on FNA-Tg in metastatic LNs might have a lower sensitivity and NPV in the TgAb-positive patients $(19,26)$. Consistent with their results, our study also showed a lower diagnostic accuracy of FNA-Tg, whether combined with FNAC or not, in the TgAb-positive patients (Table 5). However, a high proportion of patients $(55 / 273,20.1 \%)$ with high $\mathrm{TgAb}$ levels existed in our preoperative LN case series, whereas only 15 patients out of 207 (7.2\%), in Jeon et al. (21), showed high TgAb levels and were evaluated by FNA-Tg for suspicious LNs over follow-up after total thyroidectomy. These findings suggest that $\mathrm{TgAb}$ has greater effect on FNA-Tg level of preoperative patients and justify $\mathrm{TgAb}$ measurement when planning to perform FNA-Tg evaluation before surgery.

We measured FNA-Tg levels of 370 LNs from preoperative patients according to the presence of $\mathrm{TgAb}$. As FNA-Tg levels per se are too low in uninvolved benign LNs, the effect of $\mathrm{TgAb}$ positivity on FNA-Tg levels was negligible. On the other hand, the FNA-Tg levels from malignant LNs were significantly high, indicating that serum $\mathrm{TgAb}$ positivity might affect FNA-Tg as well as sTg. Usually, women showed a higher rate of TgAb positivity than men. This could be explained by the higher prevalence of autoimmune thyroiditis in women than men (29). 
Our results indicated that FNA-Tg had a high NPV, a characteristic of a good diagnostic tool. Diagnostic performance of the combination of FNAC and FNA-Tg levels was better than the single use of FNAC or FNA-Tg (Table 4). When we used an FNA-Tg cutoff value of $6.0 \mathrm{ng} / \mathrm{ml}$ for preoperative patients, the $\operatorname{TgAb}$ - group showed the best diagnostic performance, but lower sensitivity and NPV were shown in the $\mathrm{Tg} A \mathrm{~b}+$ group. In comparison, lowering the FNA-Tg cutoff value led to increased sensitivity and NPV in the TgAb + group (Table 5). This finding supported the hypothesis that the cutoff level of FNA-Tg in TgAb+ group should be lower than in the $\mathrm{TgAb}-$ group. Interestingly, combining FNAC with FNA-Tg showed the same sensitivity but lower specificity in the $\mathrm{TgAb}$ - group, because of one false-positive FNAC result.

It has been suggested that sTg level should be considered with FNA-Tg by sTg to FNA-Tg ratio (23, 30, 31 ). This approach could potentially overcome interference by sTg with FNA-Tg, especially in preoperative patients, and therefore needs validation. In our study, a serum-to-FNA-Tg ratio of 1.0 had an $88.1 \%$ sensitivity and 93.9\% specificity, which showed inferiority to FNA-Tg alone or FNA-Tg combined with FNAC (Table 4).

Generally, FNAC, FNA-Tg levels and their combination had lower diagnostic performance in $\mathrm{TgAb}+$ group compared to the $\mathrm{TgAb}-$ group. These results indicated that a positive $\mathrm{TgAb}$ status has a low diagnostic rate at any cutoff level (Table 5). According to the current guidelines, there is no recommendation to measure serum TgAb levels preoperatively (16). However, TgAb should be measured in preoperative thyroid cancer patients with planned FNAC or FNA-Tg assays for suspicious LNs. Our results suggested a lowering of cutoff value of FNA-Tg levels when $\mathrm{TgAb}$ is present in patient serum.

For evaluation of FNAC on LN, we used the conventional smear (CS) method rather than LBC. There were several studies that showed better diagnostic performance in LBC than in CS in evaluating thyroid nodule $(18,32)$. However, there were rarely studies showing the usefulness of LBC in FNAC of the LN. One study showed that the diagnostic efficacy of FNAC of the LN is identical between the CS and LBC (33). In another study by Tripathy et al. (34) that evaluated 40 LNs (20 reactive hyperplasia, 12 granulomatous lymphadenitis, three lymphoma and five metastatic carcinoma), Reed-Sternberg cells were more easily diagnosed on LBC smears due to mono-layering. From a few prior studies, we could see the potential of LBC in FNA-Tg diagnosis. In the near future, comparative study should be included between LBC and the CS method for the improvement of diagnostic efficacy in LN FNAC.
The strength of this study was that all 370 LNs in 273 patients were preoperative cases that had never been assessed in detail up to that point. However, we did not measure the levels of $\mathrm{TgAb}$ in the FNA washout fluid (FNA$\mathrm{Tg} A b)$. This makes it impossible to know the exact impact of FNA-TgAb on FNA-Tg levels, even though FNA-TgAb is unlikely to have an influence on FNA-Tg levels, according to several reports $(35,36)$ : first, the high $\mathrm{Tg}$ levels in metastatic LN (FNA-Tg) overcomes the blocking capacity of FNA-TgAb. Secondly, the FNA-TgAb is too low to interfere. Another limitation was that all suspicious LNs evaluated by FNAC and FNA-Tg were not pathologically confirmed. The LNs considered to be benign by FNAC were not the target of surgery, hence their final outcomes were dependent on follow-up US in 6-12 months.

\section{Conclusion}

Our data indicated that serum $\operatorname{TgAb}$ should be measured along with FNAC and FNA-Tg on suspicious LNs in preoperative patients, due to the different cutoff values of FNA-Tg based on serum TgAb status. We propose that the cutoff value of FNA-Tg should be lowered before thyroidectomy in thyroid cancer patients with positive serum TgAb.

Declaration of interest

The authors declare that there is no conflict of interest that could be perceived as prejudicing the impartiality of the research reported.

\section{Funding}

This research did not receive any specific grant from any funding agency in the public, commercial or not-for-profit sector.

\section{References}

1 Schlumberger MJ. Medical progress - papillary and follicular thyroid carcinoma. New England Journal of Medicine 1998338 297-306. (doi:10.1056/NEJM199801293380506)

2 Johnson NA \& Tublin ME. Postoperative surveillance of differentiated thyroid carcinoma: rationale, techniques and controversies. Radiology 2008249 429-444. (doi:10.1148/radiol.2492071313)

3 Cunha N, Rodrigues F, Curado F, Ilheu O, Cruz C, Naidenov P, Rascao MJ, Ganho J, Gomes I, Pereira H et al. Thyroglobulin detection in fine-needle aspirates of cervical lymph nodes: a technique for the diagnosis of metastatic differentiated thyroid cancer. European Journal of Endocrinology 2007157 101-107. (doi:10.1530/EJE-07-0088)

$4 \mathrm{Kwak}$ JY. Indications for fine needle aspiration in thyroid nodules. Endocrinology and Metabolism 201328 81-85. (doi:10.3803/EnM.2013. 28.2.81)

5 Boi F, Baghino G, Atzeni F, Lai ML, Faa G \& Mariotti S. The diagnostic value for differentiated thyroid carcinoma metastases of thyroglobulin 
(Tg) measurement in washout fluid from fine-needle aspiration biopsy of neck lymph nodes is maintained in the presence of circulating anti-Tg antibodies. Journal of Clinical Endocrinology and Metabolism 2006 91 1364-1369. (doi:10.1210/jc.2005-1705)

6 Baloch ZW, Barroeta JE, Walsh J, Gupta PK, Livolsi VA, Langer JE \& Mandel SJ. Utility of thyroglobulin measurement in fine-needle aspiration biopsy specimens of lymph nodes in the diagnosis of recurrent thyroid carcinoma. CytoJournal 20085 1. (doi:10.1186/ 1742-6413-5-1)

7 Sohn YM, Kim MJ, Kim EK \& Kwak JY. Diagnostic performance of thyroglobulin value in indeterminate range in fine needle aspiration washout fluid from lymph nodes of thyroid cancer. Yonsei Medical Journal 201253 126-131. (doi:10.3349/ymj.2012.53.1.126)

8 Mikosinski S, Pomorski L, Oszukowska L, Makarewicz J, Adamczewski Z, Sporny S \& Lewinski A. The diagnostic value of thyroglobulin concentration in fine-needle aspiration of the cervical lymph nodes in patients with differentiated thyroid cancer. Endokrynologia Polska 2006 57 392-395.

9 Jung JY, Shin JH, Han BK \& Ko EY. Optimized cutoff value and indication for washout thyroglobulin level according to ultrasound findings in patients with well-differentiated thyroid cancer. AJNR. American Journal of Neuroradiology 201334 2349-2353. (doi:10.3174/ajnr.A3687)

10 Frasoldati A, Toschi E, Zini M, Flora M, Caroggio A, Dotti C \& Valcavi R. Role of thyroglobulin measurement in fine-needle aspiration biopsies of cervical lymph nodes in patients with differentiated thyroid cancer. Thyroid 19999 105-111. (doi:10.1089/thy.1999.9.105)

11 Grani G \& Fumarola A. Thyroglobulin in lymph node fine-needle aspiration wash-out: a systematic review and meta-analysis of diagnostic accuracy. Journal of Clinical Endocrinology and Metabolism 201499 1970-1982. (doi: 10.1210/jc.2014-1098)

12 Torres MR, Nobrega Neto SH, Rosas RJ, Martins AL, Ramos AL \& da Cruz TR. Thyroglobulin in the washout fluid of lymph-node biopsy: what is its role in the follow-up of differentiated thyroid carcinoma? Thyroid 201424 7-18. (doi:10.1089/thy.2013.0244)

13 Moon JH, Kim YI, Lim JA, Choi HS, Cho SW, Kim KW, Park HJ, Paeng JC, Park YJ, Yi KH et al. Thyroglobulin in washout fluid from lymph node fine-needle aspiration biopsy in papillary thyroid cancer: large-scale validation of the cutoff value to determine malignancy and evaluation of discrepant results. Journal of Clinical Endocrinology and Metabolism 201398 1061-1068. (doi:10.1210/jc. 2012-3291)

14 Leenhardt L, Erdogan MF, Hegedus L, Mandel SJ, Paschke R, Rago T \& Russ G. European thyroid association guidelines for cervical ultrasound scan and ultrasound-guided techniques in the postoperative management of patients with thyroid cancer. European Thyroid Journal 20132 147-159. (doi:10.1159/000354537)

15 Yi KH, Park YJ, Koong S-S, Kim J-H, Na DG, Ryu J-S, Park SY, Park IA, Baek C-H, Shong YK et al. Revised Korean Thyroid Association management Guidelines for patients with thyroid nodules and thyroid cancer. Endocrinology and Metabolism 201025 270-297. (doi:10.3803/ EnM.2010.25.4.270)

16 Cooper DS, Doherty GM, Haugen BR, Kloos RT, Lee SL, Mandel SJ, Mazzaferri EL, McIver B, Pacini F, Schlumberger M et al. Revised American Thyroid Association management guidelines for patients with thyroid nodules and differentiated thyroid cancer. Thyroid 2009 19 1167-1214. (doi:10.1089/thy.2009.0110)

17 Kim ES, Lim DJ, Baek KH, Lee JM, Kim MK, Kwon HS, Song KH, Kang MI, Cha BY, Lee KW et al. Thyroglobulin antibody is associated with increased cancer risk in thyroid nodules. Thyroid 201020 885-891. (doi:10.1089/thy.2009.0384)

18 Jung CK, Lee A, Jung ES, Choi YJ, Jung SL \& Lee KY. Split sample comparison of a liquid-based method and conventional smears in thyroid fine needle aspiration. Acta Cytologica 200852 313-319. (doi:10.1159/000325513)
19 Kim MJ, Kim EK, Kim BM, Kwak JY, Lee EJ, Park CS, Cheong WY \& Nam KH. Thyroglobulin measurement in fine-needle aspirate washouts: the criteria for neck node dissection for patients with thyroid cancer. Clinical Endocrinology 200970 145-151. (doi:10.1111/j.13652265.2008.03297.x)

20 Salmaslioglu A, Erbil Y, Citlak G, Ersoz F, Sari S, Olmez A, Tunaci M, Yilmazbayhan D, Colak N \& Ozarmagan S. Diagnostic value of thyroglobulin measurement in fine-needle aspiration biopsy for detecting metastatic lymph nodes in patients with papillary thyroid carcinoma. Langenbeck's Archives of Surgery 2011396 77-81. (doi:10.1007/s00423-010-0723-1)

21 Jeon MJ, Park JW, Han JM, Yim JH, Song DE, Gong G, Kim TY, Baek JH, Lee JH, Shong YK et al. Serum antithyroglobulin antibodies interfere with thyroglobulin detection in fine-needle aspirates of metastatic neck nodes in papillary thyroid carcinoma. Journal of Clinical Endocrinology and Metabolism 201398 153-160. (doi:10.1210/ jc.2012-2369)

22 Snozek CL, Chambers EP, Reading CC, Sebo TJ, Sistrunk JW, Singh RJ \& Grebe SK. Serum thyroglobulin, high-resolution ultrasound, and lymph node thyroglobulin in diagnosis of differentiated thyroid carcinoma nodal metastases. Journal of Clinical Endocrinology and Metabolism 200792 4278-4281. (doi:10.1210/jc.2007-1075)

23 Chung J, Kim EK, Lim H, Son EJ, Yoon JH, Youk JH, Kim JA, Moon HJ \& Kwak JY. Optimal indication of thyroglobulin measurement in fine-needle aspiration for detecting lateral metastatic lymph nodes in patients with papillary thyroid carcinoma. Head \& Neck 201436 795-801. (doi:10.1002/hed.23371)

24 Kim DW, Jeon SJ \& Kim CG. Usefulness of thyroglobulin measurement in needle washouts of fine-needle aspiration biopsy for the diagnosis of cervical lymph node metastases from papillary thyroid cancer before thyroidectomy. Endocrine 201242 399-403. (doi:10.1007/s12020-0129636-9)

25 Sigstad E, Heilo A, Paus E, Holgersen K, Groholt KK, Jorgensen LH, Bogsrud TV, Berner A \& Bjoro T. The usefulness of detecting thyroglobulin in fine-needle aspirates from patients with neck lesions using a sensitive thyroglobulin assay. Diagnostic Cytopathology 200735 761-767. (doi:10.1002/dc.20726)

26 Baskin HJ. Detection of recurrent papillary thyroid carcinoma by thyroglobulin assessment in the needle washout after fine-needle aspiration of suspicious lymph nodes. Thyroid 200414 959-963. (doi:10.1089/thy.2004.14.959)

27 Spencer CA, Takeuchi M, Kazarosyan M, Wang CC, Guttler RB, Singer PA, Fatemi S, LoPresti JS \& Nicoloff JT. Serum thyroglobulin autoantibodies: prevalence, influence on serum thyroglobulin measurement, and prognostic significance in patients with differentiated thyroid carcinoma. Journal of Clinical Endocrinology and Metabolism 199883 1121-1127.

28 Spencer CA. Challenges of serum thyroglobulin (Tg) measurement in the presence of Tg autoantibodies. Journal of Clinical Endocrinology and Metabolism 200489 3702-3704. (doi:10.1210/jc.2004-0986)

29 Office on Women's Health USDoHaHS. "Hashimoto's disease fact sheet". http://www.womenshealth.gov/publications/our-publications/ fact-sheet/hashimoto-disease.html 2012.

30 Jeon SJ, Kim E, Park JS, Son KR, Baek JH, Kim YS, Park do J, Cho BY \& Na DG. Diagnostic benefit of thyroglobulin measurement in fineneedle aspiration for diagnosing metastatic cervical lymph nodes from papillary thyroid cancer: correlations with US features. Korean Journal of Radiology 200910 106-111. (doi:10.3348/kjr.2009.10.2.106)

31 Uruno T, Miyauchi A, Shimizu K, Tomoda C, Takamura Y, Ito Y, Miya A, Kobayashi K, Matsuzuka F, Amino N et al. Usefulness of thyroglobulin measurement in fine-needle aspiration biopsy specimens for diagnosing cervical lymph node metastasis in patients with papillary thyroid cancer. World Journal of Surgery 200529 483-485. (doi:10.1007/s00268004-7701-0)

32 Chang H, Lee E, Lee H, Choi J, Kim A \& Kim BH. Comparison of diagnostic values of thyroid aspiration samples using liquid-based 
preparation and conventional smear: one-year experience in a single institution. APMIS 2013121 139-145. (doi:10.1111/j.1600-0463. 2012.02944.x)

33 Garbar C, Remmelink M \& Mascaux C. Fine needle aspiration cytology of lymph node: experience of 2 university hospitals with conventional smears and liquid-based cytology. Acta Cytologica 200852 418-423. (doi:10.1159/000325546)

34 Tripathy K, Misra A \& Ghosh JK. Efficacy of liquid-based cytology versus conventional smears in FNA samples. Journal of Cytology 201532 17-20. (doi:10.4103/0970-9371.155225)
35 Spencer C \& Fatemi S. Thyroglobulin antibody (TgAb) methods - strengths, pitfalls and clinical utility for monitoring TgAb-positive patients with differentiated thyroid cancer. Best Practice \& Research. Clinical Endocrinology \& Metabolism 201327 701-712. (doi:10.1016/j.beem. 2013.07.003)

36 Verburg FA, Luster M, Cupini C, Chiovato L, Duntas L, Elisei R, Feldt-Rasmussen U, Rimmele H, Seregni E, Smit JW et al. Implications of thyroglobulin antibody positivity in patients with differentiated thyroid cancer: a clinical position statement. Thyroid $2013 \mathbf{2 3}$ 1211-1225. (doi:10.1089/thy.2012.0606)

Received 30 March 2015

Revised version received 2 July 2015

Accepted 22 July 2015 